\title{
Secondary Ozone Peaks in the troposphere over the Himalayas
}

\section{N. Ojha (1), A. Pozzer (1), D. Akritidis (1, 2), J. Lelieveld $(1,3)$}

s 1 Atmospheric Chemistry Department, Max Planck Institute for Chemistry,

6 Mainz, Germany

2 Department of Meteorology and Climatology, School of Geology, Aristotle University of Thessaloniki, Thessaloniki, Greece

3 Energy, Environment and Water Research Center, The Cyprus Institute, Nicosia, 


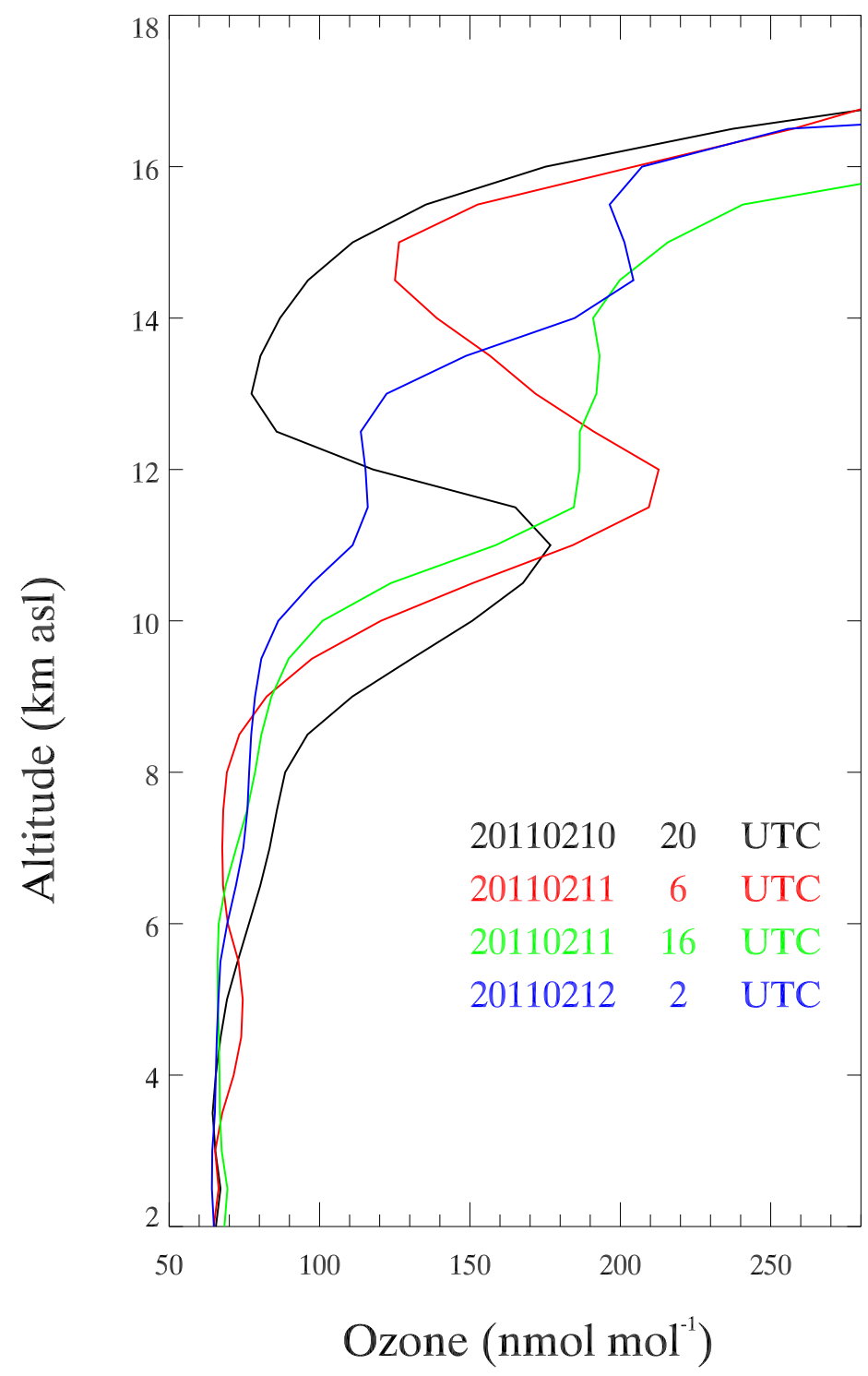

Figure 1: EMAC simulated time-evolution of ozone vertical profiles at each model time step during 10-12 Feb 2011. 